\title{
Leaching of $\mathrm{CuO}$ nanoparticles from PES ultrafiltration membranes
}

Alfred Kajau, Machawe Motsa, Bhekie B. Mamba and Oranso Mahlangu*

Institute for Nanotechnology and Water Sustainability, College of Engineering, Science and Technology, University of South Africa, Florida Science Campus, 1709 Roodepoort, South Africa

*Correspondence: mahlaot@unisa.ac.za; orathem@gmail.com 


\section{Supporting Information}

Table S1: ICP-MS operational conditions

\begin{tabular}{ll}
\hline Parameter & ICP-MS \\
\hline RF power, W & 1500 \\
Plasma gas flow rate, Lmin'-1 & 17 \\
Auxiliary gas flow rate, Lmin'-1 & 1.2 \\
Carrier gas flow rate, Lmin'-1 & 0.92 \\
Scan/ reading & 50 \\
Reading & 1 \\
Replicates & 3 \\
Detector & Dual \\
Cones sampler/ skimmer & Pt \\
\hline
\end{tabular}



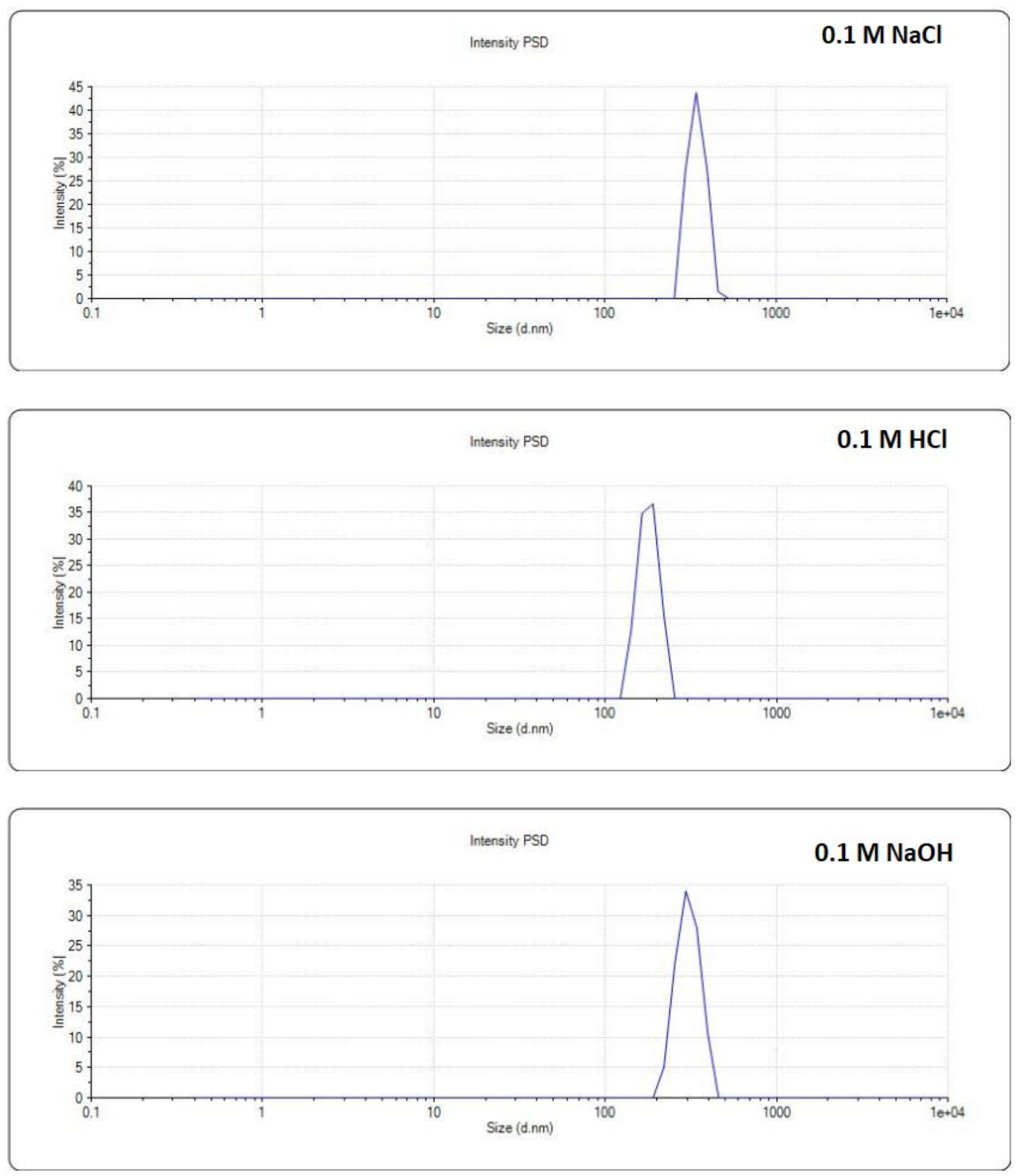

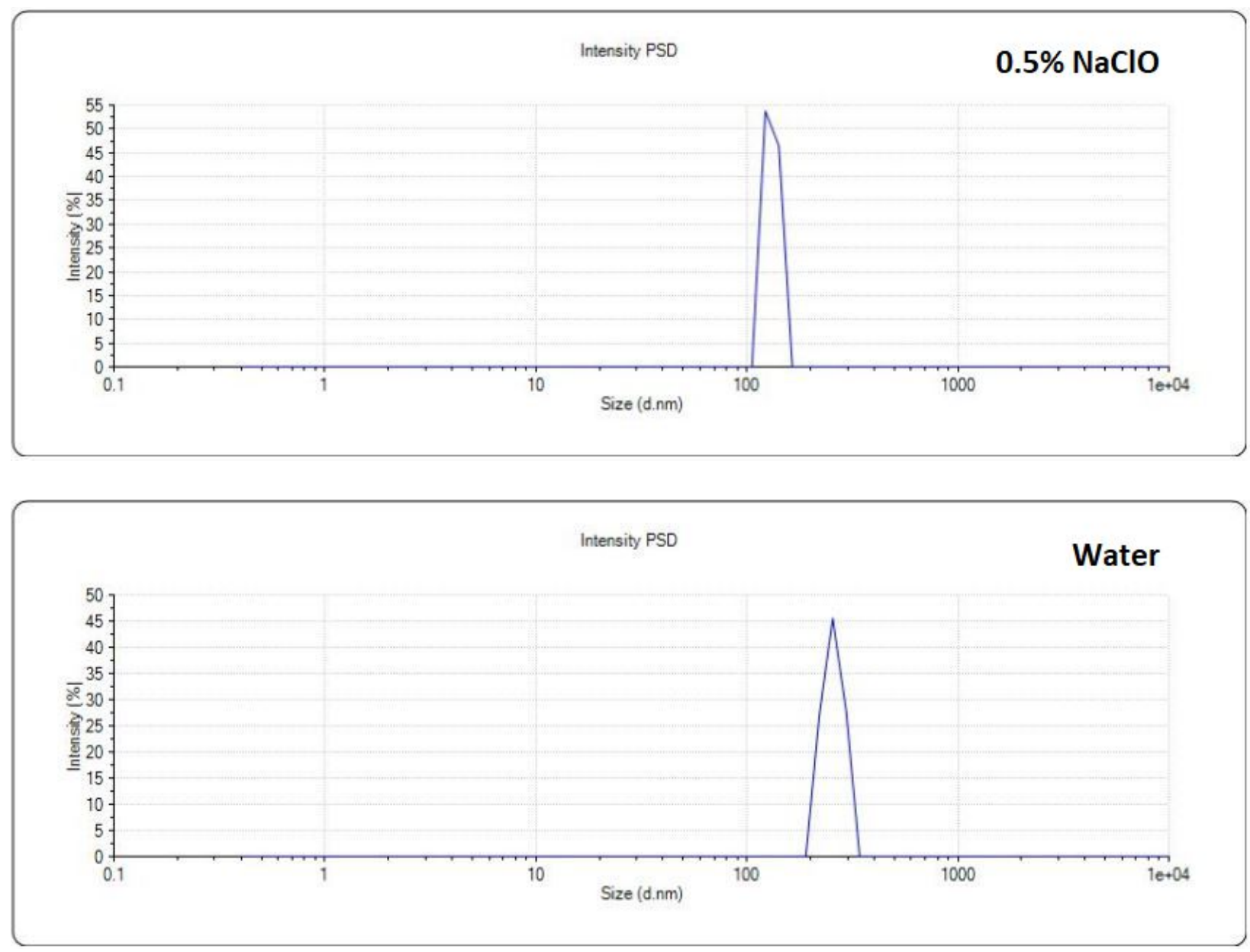

Figure S1: Dynamic light scattering results of cleaning solutions after leaching experiments. 

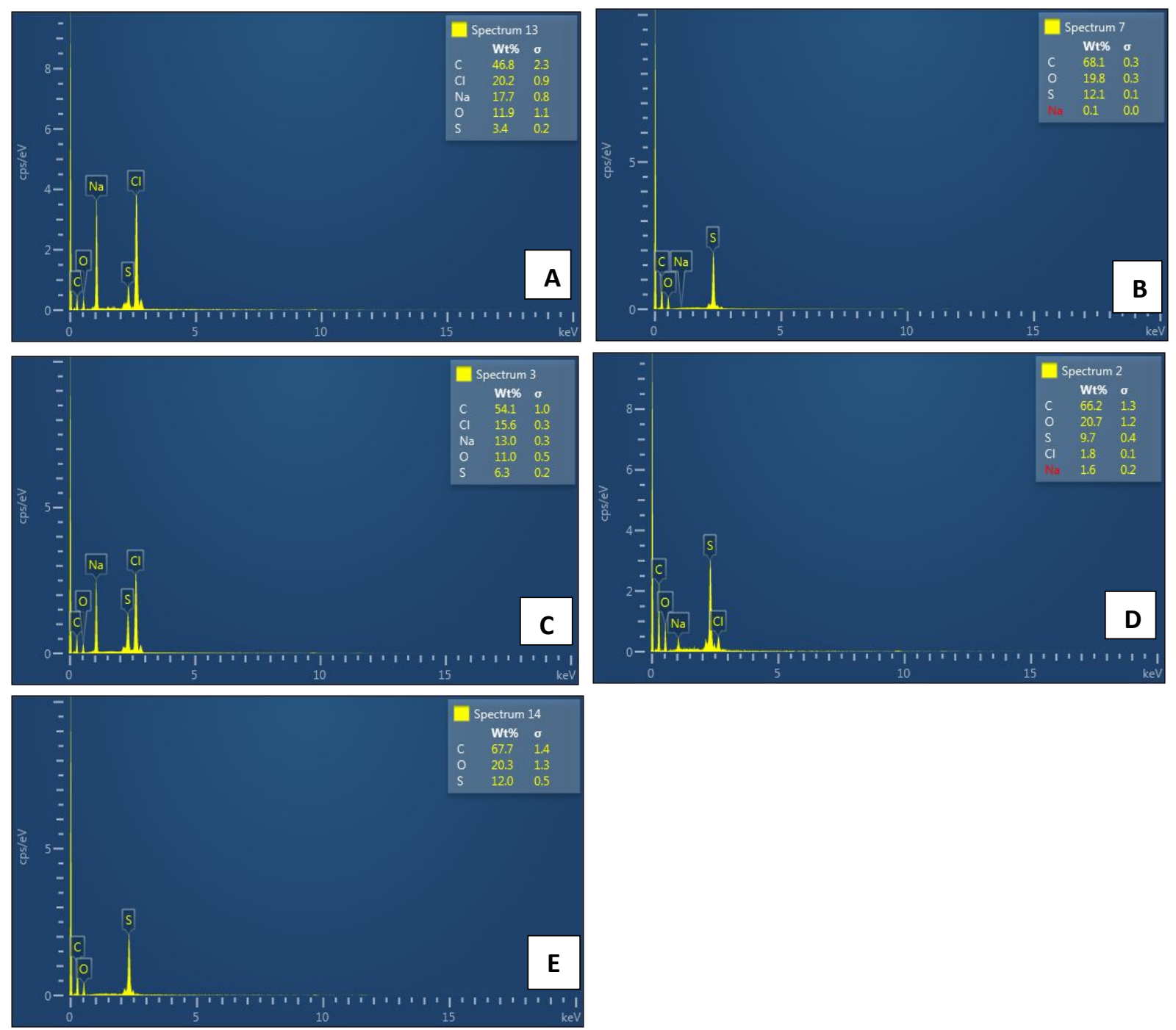

Figure S2: EDS spectra of solutions used in cleaning PES membranes without $\mathrm{CuO}$ and deposited on neat PES membranes: A - cleaned with $0.1 \mathrm{M} \mathrm{NaCl}$; $\mathrm{B}$ - cleaned with 0.1 $\mathrm{M} \mathrm{HCl} ; \mathrm{C}$ - cleaned with $0.1 \mathrm{M} \mathrm{NaOH}$; D - cleaned with $0.5 \% \mathrm{NaClO}$ and $\mathrm{E}$ - cleaned with water 

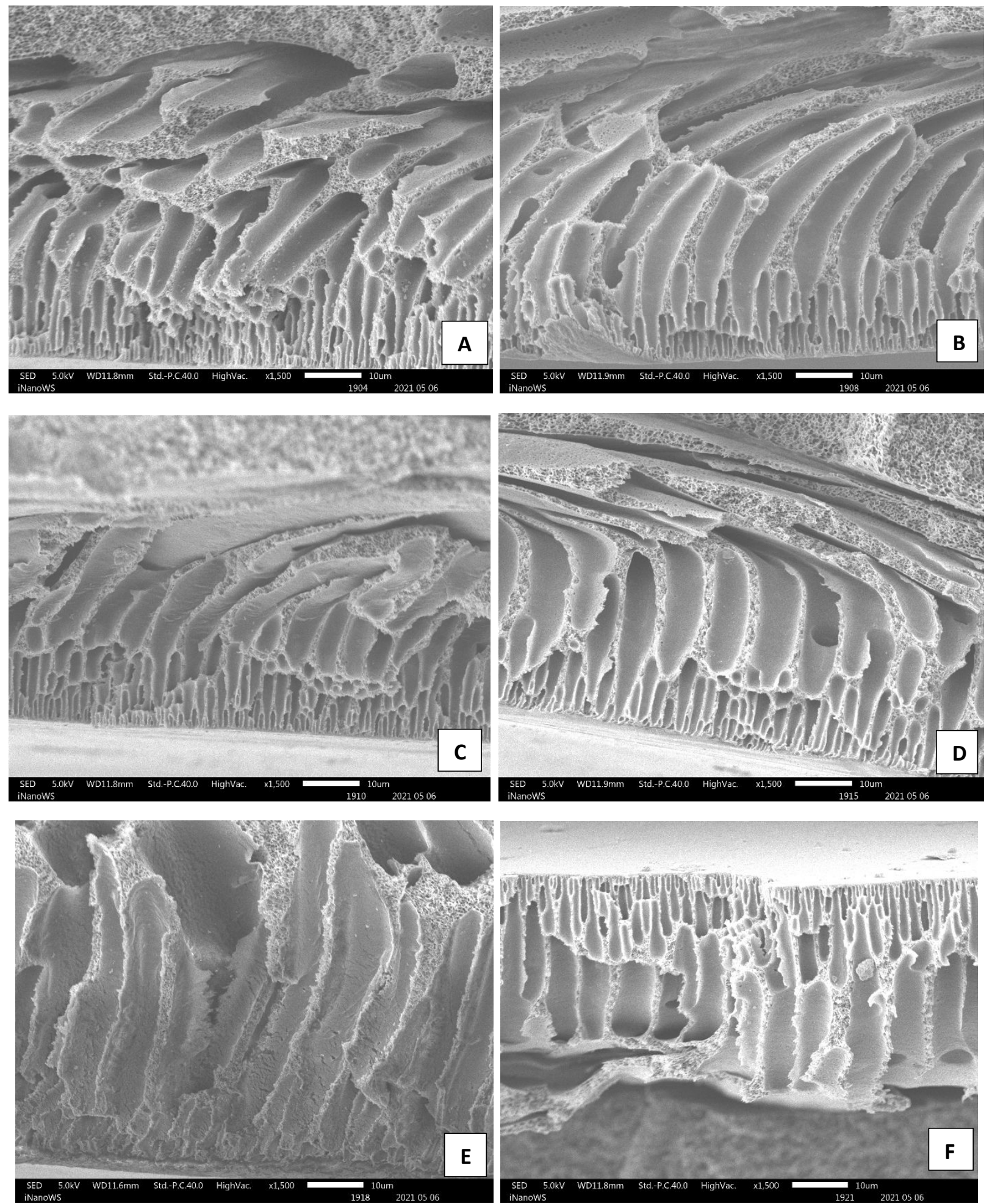

Figure S3: Surface micrographs of PES membranes exposed to different cleaning solutions: A - Not cleaned; B - cleaned with $0.1 \mathrm{M} \mathrm{NaCl}$; C - cleaned with $0.1 \mathrm{M} \mathrm{HCl}$; D - cleaned with $0.1 \mathrm{M} \mathrm{NaOH} ; \mathrm{E}$ - cleaned with $0.5 \% \mathrm{NaClO}$ and $\mathrm{F}$ - cleaned with water 


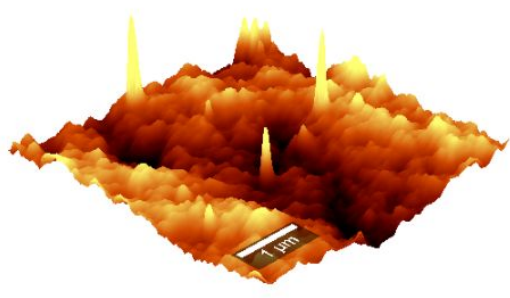

PES not leached

$\mathrm{Sa}=4.2 \mathrm{~nm}$

$\mathrm{Sq}=5.2 \mathrm{~nm}$

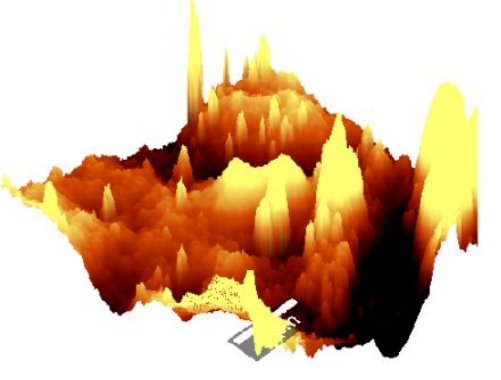

$0.1 \mathrm{M} \mathrm{NaOH}$

$\mathrm{Sa}=10.7 \mathrm{~nm}$
$\mathrm{Sq}=15.4 \mathrm{~nm}$

$\mathrm{Sq}=15.4 \mathrm{~nm}$
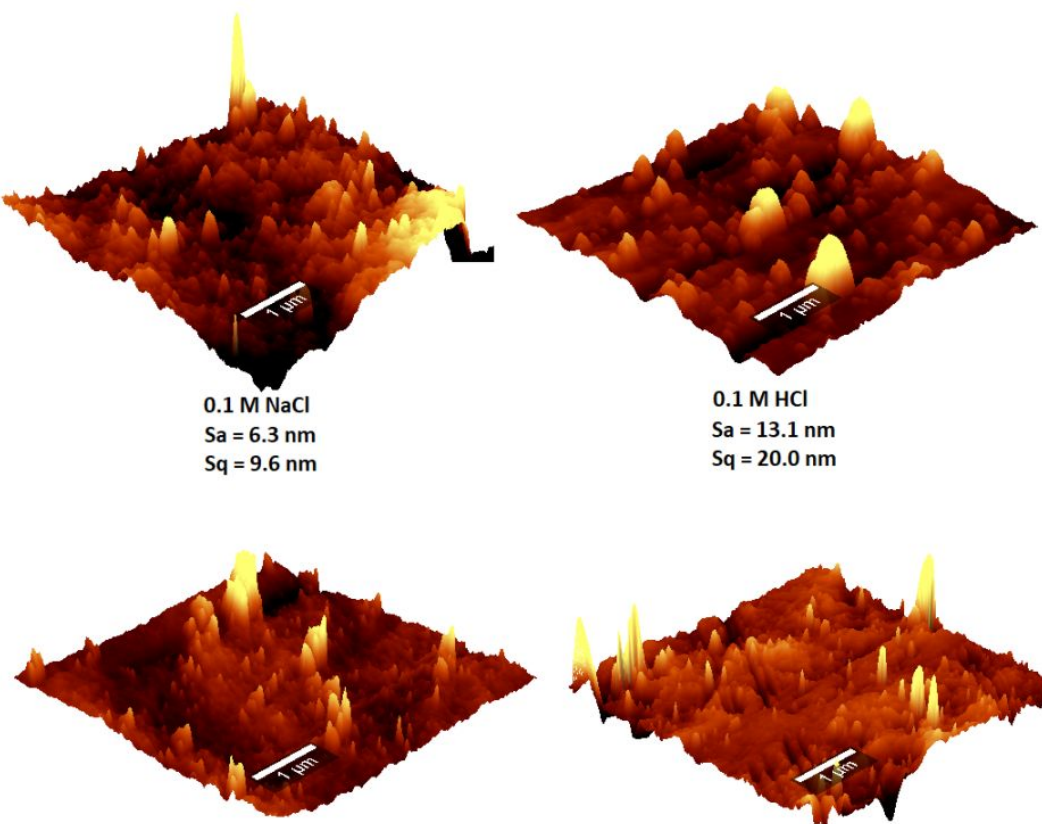

$0.5 \% \mathrm{NaClO}$

$\mathrm{Sa}=5.5 \mathrm{~nm}$
$\mathrm{Sq}=8.4 \mathrm{~nm}$

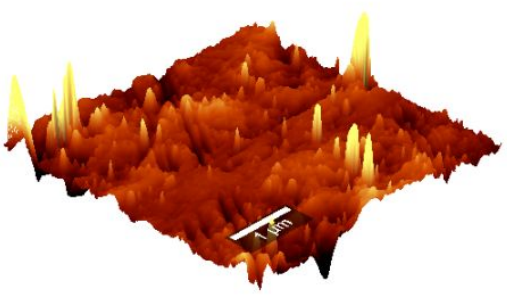

Water

$\mathrm{Sa}=5.8 \mathrm{~nm}$ $\mathrm{Sq}=8.7 \mathrm{~nm}$

Figure S4: AFM micrographs of PES membranes before and after $840 \mathrm{~h}$ of exposure to cleaning solutions 

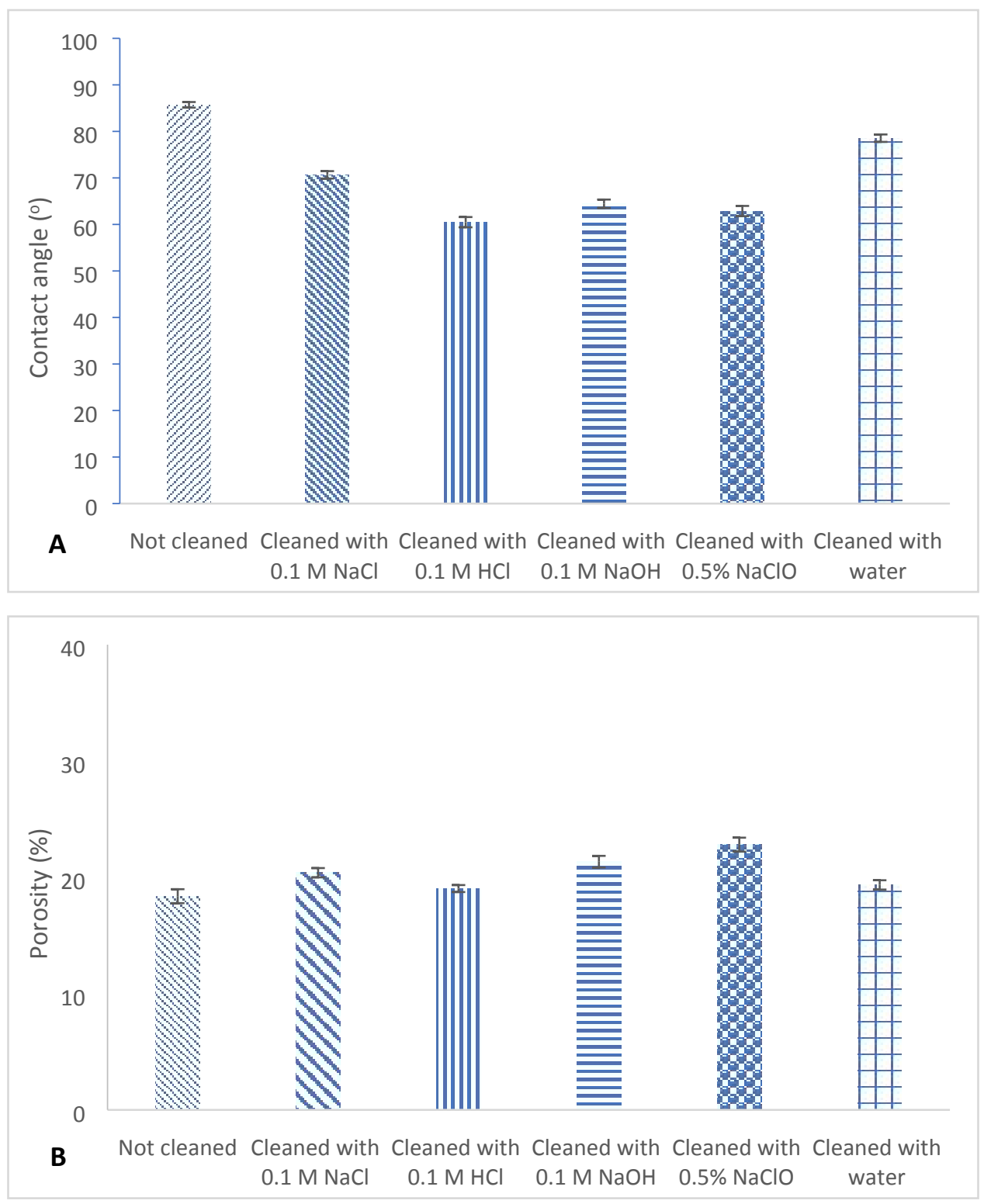

Figure S5: Contact angle measurements (A) and membrane porosity (B) of PES membranes before and after $840 \mathrm{~h}$ of exposure to cleaning solutions 